\section{Commentary: MAGA: Multiple arterial grafting agony}

\author{
Matthew C. Henn, MD, and \\ John Bozinovski, MD, MSc
}

How do you teach an old dog new tricks? Build trust, recognize and respect the canine's limits, keep training sessions short, and never underestimate the power of positive reinforcement. Gaudino and colleagues ${ }^{1}$ eloquently and comprehensively provide support for the routine use of the radial artery (RA) conduit as well as the bilateral internal mammary arteries for multiple arterial grafting (MAG) in coronary artery bypass grafting (CABG). However, they also point out the disappointingly low use of MAG over the past several decades in the United States, and provide some compelling speculation as to why that is the case. The authors are extremely experienced in the use of RA conduit, making them uniquely positioned to gain the trust of the old dogs in the cardiac surgery profession.

The hard truth is that we as a profession have not adopted routine use of the RA conduit. In fact, the RA conduit is used in $<6 \%$ of primary isolated CABG procedures, as reported from the Society of Thoracic Surgeons database. ${ }^{2}$ Many factors contribute to the lack of RA utilization, but lack of evidence should not be one of them. While multiple observational and comparative studies have shown excellent results with RA conduit use, ${ }^{3-7}$ perhaps the most convincing data have come from the Radial Artery Database International Alliance (RADIAL) investigator group. $^{8,9}$

The RADIAL project is an individual patient data meta-analysis that included $>1000$ patients from 6 randomized clinical trials that compared the use of RA conduits vs saphenous vein conduits as the second conduit

\footnotetext{
From the Division of Cardiac Surgery, The Ohio State University Wexner Medical Center, Columbus, Ohio.

Disclosures: The authors reported no conflicts of interest.

The Journal policy requires editors and reviewers to disclose conflicts of interest and to decline handling or reviewing manuscripts for which they may have a conflict of interest. The editors and reviewers of this article have no conflicts of interest.

Received for publication Oct 12, 2020; revisions received Oct 12, 2020; accepted for publication Oct 15, 2020; available ahead of print Oct 17, 2020.

Address for reprints: John Bozinovski, MD, MSc, N816A Doan Hall, 410 West 10th Ave, Columbus, OH, 43210 (E-mail: jovan.bozinovski@osumc.edu).

J Thorac Cardiovasc Surg 2021;162:1553-4

$0022-5223 / \$ 36.00$

Copyright (c) 2020 by The American Association for Thoracic Surgery

https://doi.org/10.1016/j.jtcvs.2020.10.040
}

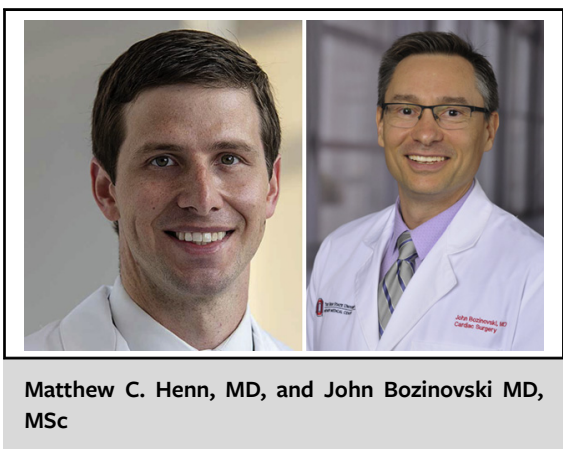

CENTRAL MESSAGE

Multiple arterial grafting (MAG) is superior to single arterial grafting, and use of the radial artery is easily learned but is underutilized. Establishing MAG as the standard of care is needed.

for CABG with a minimum of 2 years of follow-up. The 5 -year ${ }^{9}$ and 10 -year ${ }^{8}$ results demonstrated superior patency of the RA vs the saphenous vein at 5 years $(91.9 \%$ vs $80.1 \% ; P<.001)$ and improved clinical outcomes with reduced death, myocardial infarction, or repeat revascularization in patients with RA grafting at 5 years $(12.5 \%$ vs $18.7 \% ; P=.01)$ and 10 years (hazard ratio, $0.73 ; 95 \%$ confidence interval, $0.61-0.88){ }^{8,9}$

One of the primary limitations is a lack of confidence in the technique, likely resulting from a lack of training and familiarity for the surgeon and the team. However, the technique of RA harvest and use as a conduit are easily learned and adopted with a committed surgical team. Gaudino et $\mathrm{al}^{10}$ composed an excellent primer on the technical aspects of RA conduit use that covers preoperative planning, surgical strategy, technical details, and postoperative management. ${ }^{10}$

With mounting evidence on the benefits of RA use, it is time to provide even greater incentive for its use. Such an incentive may just be the type of positive reinforcement that would produce wider RA use in surgical practice. All cardiac surgeons performing $\mathrm{CABG}$ should learn the technique and be familiar with use of the RA conduit, and if they are not going to use it, to have a reason why. Our task as cardiac surgeons is to establish MAG as the standard of care if we believe it to be so; then policy can be pursued to realize that goal. We can better proclaim the value of MAG to our cardiology colleagues and enlist their support. We need to recognize that contemporary surgical coronary 
revascularization covers such a breadth and depth of techniques that it is becoming a subspecialty within cardiac surgery, and consider establishing CABG fellowships. Those performing MAG need to impart the philosophy to trainees and practice partners not already facile with MAG.

\section{References}

1. Gaudino M, Kurlansky P, Fremes S. The use of the radial artery for coronary artery bypass grafting improves long-term outcomes: and now what? J Thorac Cardiovasc Surg. 2021;162:1548-15552.

2. Aldea GS, Bakaeen FG, Pal J, Fremes S, Head SJ, Sabik J, et al. The Society of Thoracic Surgeons clinical practice guidelines on arterial conduits for coronary artery bypass grafting. Ann Thorac Surg. 2016;101:801-9.

3. Gaudino M, Tondi P, Benedetto U, Milazzo V, Flore R, Glieca F, et al. Radial artery as a coronary artery bypass conduit: 20-year results. J Am Coll Cardiol. 2016;68:603-10.

4. Gaudino M, Rahouma M, Abouarab A, Leonard J, Kamel M, Di Franco A, et al. Radial artery versus saphenous vein as the second conduit for coronary artery bypass surgery: a meta-analysis. J Thorac Cardiovasc Surg. 2019;157:1819-25.
5. Deb S, Cohen EA, Singh SK, Une D, Laupacis A, Fremes SE, et al. Radial artery and saphenous vein patency more than 5 years after coronary artery bypass surgery: results from RAPS (Radial Artery Patency Study). J Am Coll Cardiol. 2012; 60:28-35.

6. Goldman S, Sethi GK, Holman W, Thai H, McFalls E, Ward HB, et al. Radial artery grafts vs saphenous vein grafts in coronary artery bypass surgery: a randomized trial. JAMA. 2011;305:167-74.

7. Collins P, Webb CM, Chong CF, Moat NE, Radial Artery Versus Saphenous Vein Patency Trial Investigators. Radial artery versus saphenous vein patency randomized trial: five-year angiographic follow-up. Circulation. 2008;117: 2859-64.

8. Gaudino M, Benedetto U, Fremes S, Ballman K, Biondi-Zoccai G, Sedrakyan A, et al. Association of radial artery graft vs saphenous vein graft with long-term cardiovascular outcomes among patients undergoing coronary artery bypass grafting: a systematic review and meta-analysis. JAMA. 2020;324: 179-87.

9. Gaudino M, Benedetto U, Fremes S, Biondi-Zoccai G, Sedrakyan A, Puskas JD, et al. Radial-artery or saphenous-vein grafts in coronary-artery bypass surgery. $N$ Engl J Med. 2018;378:2069-77.

10. Gaudino M, Fremes S, Schwann TA, Tatoulis J, Wingo M, Tranbaugh RF. Technical aspects of the use of the radial artery in coronary artery bypass surgery. Ann Thorac Surg. 2019;108:613-22.

\section{Commentary: All we like iSheep: Reflections of an early adopter}

\author{
Fraser D. Rubens, MD
}

In this manuscript, Gaudino, Kurlansky, and Fremes ${ }^{1}$ have presented a convincing claim that the use of the radial artery as a second arterial conduit in coronary artery bypass grafting has failed to penetrate daily practice despite overpowering evidence of its clinical value on long-term outcomes. There are few investigators better positioned to collate these data, as they have contributed the most important articles on this topic. However, the reader is left with the nagging reservation that they have answered the "what," but they have not addressed the "why." We are no further ahead on

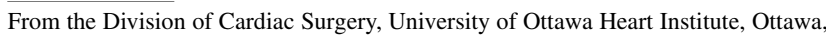
Ontario, Canada.

Disclosures: The author reported no conflicts of interest.

The Journal policy requires editors and reviewers to disclose conflicts of interest and to decline handling or reviewing manuscripts for which they may have a conflict of interest. The editors and reviewers of this article have no conflicts of interest.

Received for publication Sept 13, 2020; revisions received Sept 13, 2020; accepted for publication Sept 15, 2020; available ahead of print Sept 18, 2020.

Address for reprints: Fraser D. Rubens, MD, University of Ottawa Heart Institute, 40 Ruskin St, Ottawa, Ontario, K1Y 4W7 Canada (E-mail: frubens@ @ottawaheart.ca). J Thorac Cardiovasc Surg 2021;162:1554-5

$0022-5223 / \$ 36.00$

Copyright (c) 2020 by The American Association for Thoracic Surgery

https://doi.org/10.1016/j.jtcvs.2020.09.060

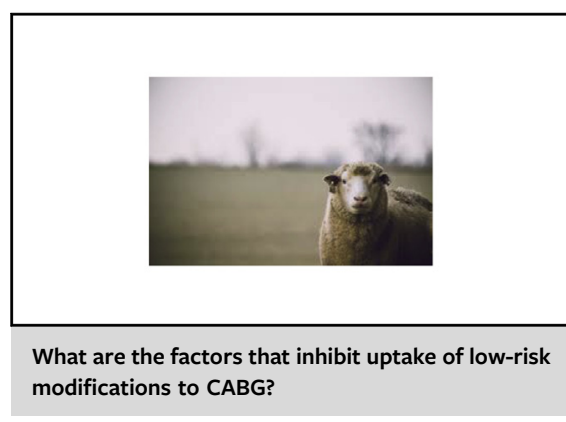

CENTRAL MESSAGE

Penetrance of radial artery use in CABG remains low. This is probably already indisputable. The time has come to figure out why we cannot change this practice pattern.

understanding why there is such a resistance to use the radial artery in the United States (this is not an issue for the rest of the world), despite the overwhelming strength of supportive data.

The essay touches base on the potential rationale of fear of increased complications; however, these arguments relate to the use of a second internal thoracic artery. Catastrophic vascular compromise of the hand after radial artery 